\title{
Effect of anterior ganglia removal on phototaxis in the earthworm (Lumbriscus terrestris)
}

\author{
JEROME BLUE \\ University of Vermont, Burlington, Vermont 05401
}

\begin{abstract}
One hundred and sixty earthworms were tested in an escape task. Half had their anterior ganglia removed $24 \mathrm{~h}$ prior to testing and half were intact. Half of each group was tested using a 100 -W light source as the aversive stimulus, the remainder using a 150-W light source. Each subject was allowed a maximum of 5 min to escape following light onset. All subjects responded faster in the high light intensity condition. Subjects with their anterior ganglia removed escaped faster than controls under the $100-\mathrm{W}$ light intensity condition, indicating the possibility that a specialized temporary lens-like and sensory cell activation follows anterior ganglia removal.
\end{abstract}

Earthworms (Lumbriscus terrestris) are photonegative to intense sources of light and photopositive to weaker sources of light (Doolittle, 1972). However, if earthworms are overexposed to light and their light receptors are satiated, they will not react to sudden increases in light intensity (Edwards \& Lofty, 1972; Hess, 1924). Edwards and Lofty (1972) also reported that the earthworm's prostomium is the most sensitive to light, the middle region less sensitive, and the posterior region least sensitive.

Removal of the supraesophageal ganglia alone results in reduced reactions to low and medium levels of illumination (Hess, 1924; Howell, 1939; Nomura, 1926; Prosser, 1934). Loss of both anterior ganglia results in loss of spontaneity and muscle tone (Bullock \& Horridge, 1965). Prosser (1934) studied the relationship between subsupraesophageal ganglia and earthworm behavior during regeneration periods and found negative phototaxis to be at a minimum 4 days following ganglia removal. The return of negatively phototaxic behavior followed the regeneration of neural tissue.

Doolittle (1972) reported results contrary to Janzen's (1931) findings that earthworms orient poorly without their anterior ganglia. Doolittle found there is no difference in their response to light whether or not their anterior ganglia are present.

The purpose of this experiment was to test the effect of anterior ganglia removal on phototaxis. Since previous experimenters used small sample sizes, the sample size in this experiment was increased. It was

The experiment reported here was carried out as part of the requirements for the Research Methodology course, Department of Psychology, University of Vermont. I am grateful to Constance A. Bush and Gladys Nieves for help in running the experiment and to Justin Joffe of the University of Vermont and John Doolittle of Sacramento State College for their many helpful suggestions. The author's present address is 40 Cochituate Road, Framingham, Massachusetts 01701. This paper was sponsored by Virginia L. Senders, who takes full editorial responsibility for its contents. observed in pilot work that earthworms with their subsupraesophageal ganglia removed were more reactive than ones with their anterior ganglia intact; the reactivity is probably due to the exposed cells and, therefore, a rest period of $24 \mathrm{~h}$ (as opposed to the $8 \mathrm{~h}$ used by many previous experimenters) was used to assure minimal postoperative excitation. Also, to exclude variations in the degree of light saturation, all subjects were kept in darkness during the 24-h rest period.

\section{METHOD}

\section{Subjects}

One hundred and sixty bisexual earthworms purchased from the Carolina Biological Supply Company (Burlington, North Carolina) were used.

\section{Apparatus}

A large container with housing material consisting of leaves, grass, wood, stems, peat moss, and pot soil was used to store the earthworms prior to experimentation. After surgery, all subjects were housed individually in $600-\mathrm{cm}^{3}$ containers, along with the housing materials, for at least $24 \mathrm{~h}$. Testing was carried out on a Formica table top marked with a 3-in.-diam circle and an 11-in.-diam circle, both sharing the same center. The circles were visible through a paper towel which covered the area. Half the earthworms were run using a $100-\mathrm{W}$ light source (ranging in temperature from $24^{\circ} \mathrm{C}$ to $34^{\circ} \mathrm{C} \pm 2^{\circ} \mathrm{C}$ at table level) positioned $23.5 \mathrm{~cm}$ above the center of the circle; the remaining half were run with a $150-\mathrm{W}$ light source (ranging in temperature from $24^{\circ} \mathrm{C}$ to $43^{\circ} \mathrm{C} \pm 2^{\circ} \mathrm{C}$ at table level) in the same position.

\section{Procedure}

Prior to surgery, all 160 worms were housed individually for $24 \mathrm{~h}$ to familiarize them with the living conditions. Eighty worms, randomly selected, were operated on according to procedures outlined by Doolittle (1972). This consisted of thoroughly slicing the earthworm between the fifth and seventh segments from the prostomium (not including the prostomium).

Twenty-four hours after surgery, subjects were placed individually on paper towel within the 3-in.-diam circle with the light off. The light was turned on and the time until the worm extended its prostomium or first segment over the radius of the 11-in.-diam circle was recorded.

The light was on throughout the trial. The subjects were run in blocks such that one subject in each group (operated and 
Table 1

Mean ( \pm SE) Escape Time (Seconds) for Subjects Tested With the $100-W$ or $150-W$ Light

\begin{tabular}{lrc}
\hline Treatment & \multicolumn{2}{c}{ Light Intensity } \\
& \multicolumn{1}{c}{$100 \mathrm{~W}$} & $150 \mathrm{~W}$ \\
\hline Operated & $51.86 \pm 6.01$ & $14.10 \pm 1.51$ \\
Control & $126.17 \pm 18.31$ & $23.16 \pm 3.03$ \\
\hline
\end{tabular}

Note. $N=40$ per group.

control) was run before a second subject from the same group. Within blocks, the order of running was random. The Formica table top was covered with damp paper towels which were replaced after each worm or dampened with distilled water to maintain a constant temperature. The room lights were off.

\section{RESULTS AND DISCUSSION}

A 2 (surgical treatment) by 2 (light intensity) analysis of variance showed that operated worms escaped significantly faster than controls $(\mathrm{F}=28.83, \mathrm{df}=1 / 116$, $\mathrm{p}<.001)$. Means are shown in Table 1 . Worms in both groups escaped significantly more rapidly in the $150-\mathrm{W}$ condition than in the $100-\mathrm{W}$ condition $(F=51.74$, $\mathrm{df}=1 / 116, \mathrm{p}<.001)$. Differences between operated and control worms at $150 \mathrm{~W}$ were not significant $(\mathrm{F}<1)$.

Earthworms without their anterior ganglia performed differently from earthworms with their anterior ganglia intact upon stimulation with intense (100-W) light. The earthworm's ganglia are apparently not necessary for photosensitivity. At a very high light intensity $(150 \mathrm{~W})$, the operated worms were not significantly faster than controls.

Doolittle (1972) found that earthworms with their ganglia removed escape from light as well as controls. The present findings confirm that there is no deficit in escape performance in operated worms and show indeed that earthworms display increased ability to escape light $(100 \mathrm{~W})$ when the anterior ganglia are removed. Edwards and Lofty (1972) stated that the earthworm's prostomium is more sensitive to light than the middle region, which in turn is more sensitive than the posterior end. The present findings may indicate that, once the prostomium of the earthworm is removed, the middle and posterior regions become more sensitive to intense sources of light. This may be due to regeneration of the ventral nerve cord. These findings are contrary to those of Prosser (1934), who studied the relationship between ganglia and earthworm behavior during the regeneration period and found negative phototaxis to recur not earlier than 4 days following ganglia removal. Prosser (1934) disregarded the possibility of some improvement in sensory capability without complete regeneration of neural tissue or the capability of the earthworm's sensory lens-like cells to adapt rapidly.

The temperature at the $100-\mathrm{W}$ light onset was approximately $24^{\circ} \mathrm{C}$ and rose fairly fast. Most worms escaped before peak temperature was reached $\left(36^{\circ} \mathrm{C}\right.$ $40^{\circ} \mathrm{C}$ ), leaving it unlikely that the $100 \mathrm{~W}$ produced motivation to avoid heat.

Nonsignificant differences between the operated and control worms at $150 \mathrm{~W}$ may perhaps be due to confounding of light escape and heat escape. The 150-W light certainly proved motivating to all worms (operated and control) and apparently the anterior ganglia do not affect the worms' escape from intense light (heat) (Doolittle, 1972). Doolittle (1972), Prosser (1934), and Smith (1902) found that the subsupraesophageal (anterior) ganglia appear to be unnecessary for the earthworm to escape strong stimuli. The meaning of "strong light" is unclear because the exact wattage was not reported in prior experiments. Smith (1902) said that the $36^{\circ} \mathrm{C}-40^{\circ} \mathrm{C}$ is unmotivating or fatal. According to him, the 150-W light should have also been fatal to the worms, since the temperature it produced ranged from $24^{\circ} \mathrm{C}$ to $43^{\circ} \mathrm{C}\left( \pm 2^{\circ} \mathrm{C}\right)$ from onset to offset. The nonsignificant differences in escape abilities of operated and control worms under the $150-\mathrm{W}$ light are probably attributable to heat. It appears that if $36^{\circ} \mathrm{C}-40^{\circ} \mathrm{C}$ heat is fatal, it has to be applied for a period longer than $5 \mathrm{~min}$. The experimental subjects might have become more activated due to the exposure of their nerve fibers. Whatever the reason, removal of the anterior ganglia does not result in loss of spontaneity and movement in response to high illumination, as reported by Bullock and Horridge (1965). Further experimentation is needed to examine the role of heat, but it is the most probable cause of nonsignificant differences between the operated and control worms with the 150-W light.

Earthworms, after being secluded in the dark, are highly reactive due to the sensitivity of the middle and posterior regions, as seen in this experiment. Possibly the sensory cells and lens-like structures in the region of the epidermis and dermis become more sensitive to light during the period that the prostomium or anterior ganglia are regenerating. The increased sensory sensitivity may be temporary, perhaps continuing only until complete regeneration has taken place. A more extensive follow-up with earthworms at longer intervals after their anterior gangiia are removed may shed more light on the possibility of lens-like and sensory cell activation or adaptation.

\section{REFERENCES}

Bullock, T. H., \& Horridge, G. A. Structure and function of the nervous system of invertebrates. San Francisco: Freeman, 1965.

Doolittle, J. H. The role of anterior ganglia in phototaxis and thigmotaxis in the earthworm. Psychonomic Science, 1972, 27, 151-152.

EDWARds, C. A., \& LofTy, J. R. Biology of earthworms. London: Chapman and Hall, 1972.

Hess. W. N. Reactions to light in the earthworm, Lumbriscus 
terrestris. Journal of Morphology and Physiology, 1924, 39. 515-542.

Howell, C. D. The responses to light in the earthworm, Pheretina agretis Goto and Hata, with special reference to the function of the nervous system. Journal of Experimental Zoology, 1939, 81, 231-259.

JANZEN, R. Bietrage zur nervenphysiologie der oligechaeten, zoologische Jahrbucher abt fuer allege meine. Zoologie und Physiologie der Tierre, 1931, 50, 51-150.

Nomura. E. Effect of light on the movements of Allolobophora foetida. Biology, 1962, 1, 293-409. (Tokohu University Science Reports, Series 4.)

Prosser, C. L. Effects of the central nervous system in response to light in Eisenia foetida Sav. Journal of Comparative Neurology, 1934, 59, 61-92.

Smith, A. C. The influence of temperature, odors, light and contact on the movement of the earthworm. American Journal of Physiology, 1902, 6, 459-486.

(Received for publication November 10, 1975.) 